(c) Copyright 2013 American Meteorological Society (AMS). Permission to use figures, tables, and brief excerpts from this work in scientific and educational works is hereby granted provided that the source is acknowledged. Any use of material in this work that is determined to be "fair use" under Section 107 of the U.S. Copyright Act September 2010 Page 2 or that satisfies the conditions specified in Section 108 of the U.S. Copyright Act (17 USC §108, as revised by P.L. 94-553) does not require the AMS's permission. Republication, systematic reproduction, posting in electronic form, such as on a web site or in a searchable database, or other uses of this material, except as exempted by the above statement, requires written permission or a license from the AMS. Additional details are provided in the AMS Copyright Policy, available on the AMS Web site located at (http://www.ametsoc.org/) or from the AMS at 617-227-2425 or copyrights@ametsoc.org. 


\title{
Quantifying Land Surface Temperature Variability for Two Sahelian Mesoscale Regions during the Wet Season
}

\author{
Martin G. De Kauwe \\ Department of Biological Sciences, Macquarie University, Sydney, New South Wales, Australia \\ CHRISTOPHER M. TAYLOR AND PHILIP P. HARRIS \\ Centre for Ecology and Hydrology, NERC, Wallingford, United Kingdom \\ GRAHAM P. WEEDON \\ Joint Centre for Hydrometeorological Research, Met Office, Wallingford, United Kingdom \\ RICHARD. J. ELLIS \\ Centre for Ecology and Hydrology, NERC, Wallingford, United Kingdom
}

(Manuscript received 25 September 2012, in final form 11 April 2013)

\begin{abstract}
Land-atmosphere feedbacks play an important role in the weather and climate of many semiarid regions. These feedbacks are strongly controlled by how the surface responds to precipitation events, which regulate the return of heat and moisture to the atmosphere. Characteristics of the surface can result in both differing amplitudes and rates of warming following rain. Spectral analysis is used to quantify these surface responses to rainfall events using land surface temperature (LST) derived from Earth observations (EOs). The authors analyzed two mesoscale regions in the Sahel and identified distinct differences in the strength of the shortterm ( $<5$ days) spectral variance, notably, a shift toward lower-frequency variability in forest pixels relative to nonforest areas and an increase in amplitude with decreasing vegetation cover. Consistent with these spectral signatures, areas of forest and, to a lesser extent, grassland regions were found to warm up more slowly than sparsely vegetated or barren pixels. The authors applied the same spectral analysis method to simulated LST data from the Joint UK Land Environment Simulator (JULES) land surface model. A reasonable level of agreement was found with the EO spectral analysis for two contrasting land surface regions. However, JULES shows a significant underestimate in the magnitude of the observed response to rain compared to EOs. A sensitivity analysis of the JULES model highlights an unrealistically high level of soil water availability as a key deficiency, which dampens the models response to rainfall events.
\end{abstract}

\section{Introduction}

Feedbacks between the land surface and atmosphere play an important role in shaping the weather and climate of many regions of the world (Koster et al. 2004). Properties of the land surface such as vegetation type and soil moisture exert a strong influence on fluxes of sensible and latent heat into the atmosphere. These fluxes

Corresponding author address: Martin G. De Kauwe, Department of Biological Sciences, Macquarie University, Balaclavia Road, Sydney NSW 2109, Australia.

E-mail: mdekauwe@gmail.com directly affect the temperature and humidity of the lower atmosphere, influencing the development of moist convection both locally (Taylor et al. 2012) and downstream (Spracklen et al. 2012) and on atmospheric circulations on scales of ten (Anthes 1984) to thousands (Charney 1975) of kilometers. In so-called land-atmosphere coupling hotspots (Koster et al. 2004), predictions on daily to centennial time scales rely on a realistic depiction of land surface fluxes within numerical models. Given the strong sensitivity of fluxes to surface properties, in tandem with often substantial spatial variability and a lack of flux observations at the scale of an atmospheric model grid box, this represents a formidable scientific challenge. 
Major initiatives in the West African hotspot of the semiarid Sahel, such as Hydrologic Atmospheric Pilot Experiment in the Sahel (HAPEX-Sahel; Goutorbe et al. 1997) and the African Monsoon Multidisciplinary Analysis (AMMA; Redelsperger et al. 2006), have made considerable efforts to observe small-scale landatmosphere processes. These have demonstrated that precipitation is the dominant control on the surface energy balance in the Sahel at a range of space and time scales (Gash et al. 1997; Mougin et al. 2009). The region experiences an intense wet season lasting typically from June to September, triggering rapid growth in vegetation. For a period of hours to several days after rain, high rates of evaporation occur directly from the bare soil surface, at the same time suppressing sensible heat and surface temperature (Wallace and Holwill 1997). As the vegetation develops, the surface fluxes become less variable from day to day because of the availability of water in the root zone (Kohler et al. 2010). This temporal flux variability is superimposed on spatial variability generated by contrasting land cover, precipitation history, and soil properties to generate a complex and evolving pattern of surface fluxes (Timouk et al. 2009). Indeed, it is the spatial variability in surface fluxes that has been shown to provide the primary land surface feedback mechanism influencing the initiation of convective storms on scales of tens of kilometers (Taylor et al. 2011).

The ability to test the depiction of the land surface energy balance in models is limited by the spatial scale of the observations: these are typically either point estimates at a few locations or gridded estimates at a coarse scale. Numerous studies have used site-level data to evaluate simulated surface fluxes in offline land surface models (e.g., Kothavala et al. 2005; Teuling et al. 2006; Schüttemeyer et al. 2008) and single column atmospheric models (e.g., Lauwaet et al. 2008) or used these data more explicitly to constrain model parameters (Saux-Picart et al. 2009). In the absence of observational benchmarks for regional surface energy fluxes across the Sahel, the potential reliability of model estimates is assessed through exercises such as the AMMA Land Model Intercomparison Project (ALMIP; Boone et al. 2009). The offline land surface models (LSMs) in ALMIP exhibit relatively low intermodel variation in $0.5^{\circ}$-scale surface flux estimates, suggesting that there is some skill in the modeling of surface processes. The ALMIP multimodel mean has been used alongside model reanalyses as a pseudo-observation when evaluating regional atmospheric models (Boone et al. 2010; Guichard et al. 2010; Xue et al. 2010). Boone et al. (2010) show that coupled models differ from the ALMIP estimate of the seasonal evolution of the surface energy partition even though all models exhibit similar surface net radiation. They note that this highlights problems with the West African monsoon simulated by atmospheric models, but it does not indicate the relative contributions from errors in land-atmosphere coupling and atmospheric processes.

Indirect evaluations of ALMIP estimates of the surface energy budget come from several studies. For example, de Rosnay et al. (2009) use ALMIP outputs to force a model of top-of-atmosphere (TOA) microwave brightness temperature for comparison with AMSR-E observations. They find that LSMs with finer vertical soil levels compare more favorably with the AMSR-E observations, suggesting that those LSMs also have better simulations of surface temperature and soil moisture. Similarly, Grippa et al. (2011) compared Gravity Recovery and Climate Experiment (GRACE) water storage anomalies with the ALMIP models and showed reasonable agreement between satellite estimates and the multimodel mean. However, both of these studies highlight how assumptions in the radiative forward model or surface retrieval can produce uncertainty in the observations that is as great as the intermodel variability.

Observations and model intercomparisons such as these are particularly useful for assessing seasonal variation at the regional atmospheric model scale but are of limited use in studying land surface behavior on the finer space and time scales where feedbacks on weather have been shown to be important (Taylor et al. 2011). With typical spatial resolution of $1-5 \mathrm{~km}$ and daily to subhourly sampling, satellite-derived land surface temperature (LST) data are potentially valuable for bridging this scale gap. These data provide an important indication of land surface state on subdaily time scales. Following rainfall, water is readily available for evapotranspiration and the LST stays close to the air temperature. Subsequently, as the surface dries, the LST increases. LST data have been used successfully in the Sahel to map mesoscale soil moisture variability (Taylor et al. 2007) and have been assimilated within a land surface scheme across the whole of Africa (Ghent et al. 2010).

This paper considers whether the spatial and temporal dynamics of LST, a proxy for surface fluxes, can provide useful information about land surface state. In particular, we assess whether it is possible to detect different responses. In this paper we implement power spectral analysis to quantify the surface response to rainfall events, using LST data derived from geostationary satellite data. This same analysis technique is used to examine how a typical LSM simulates these same responses. A sensitivity experiment is used to assess differences 


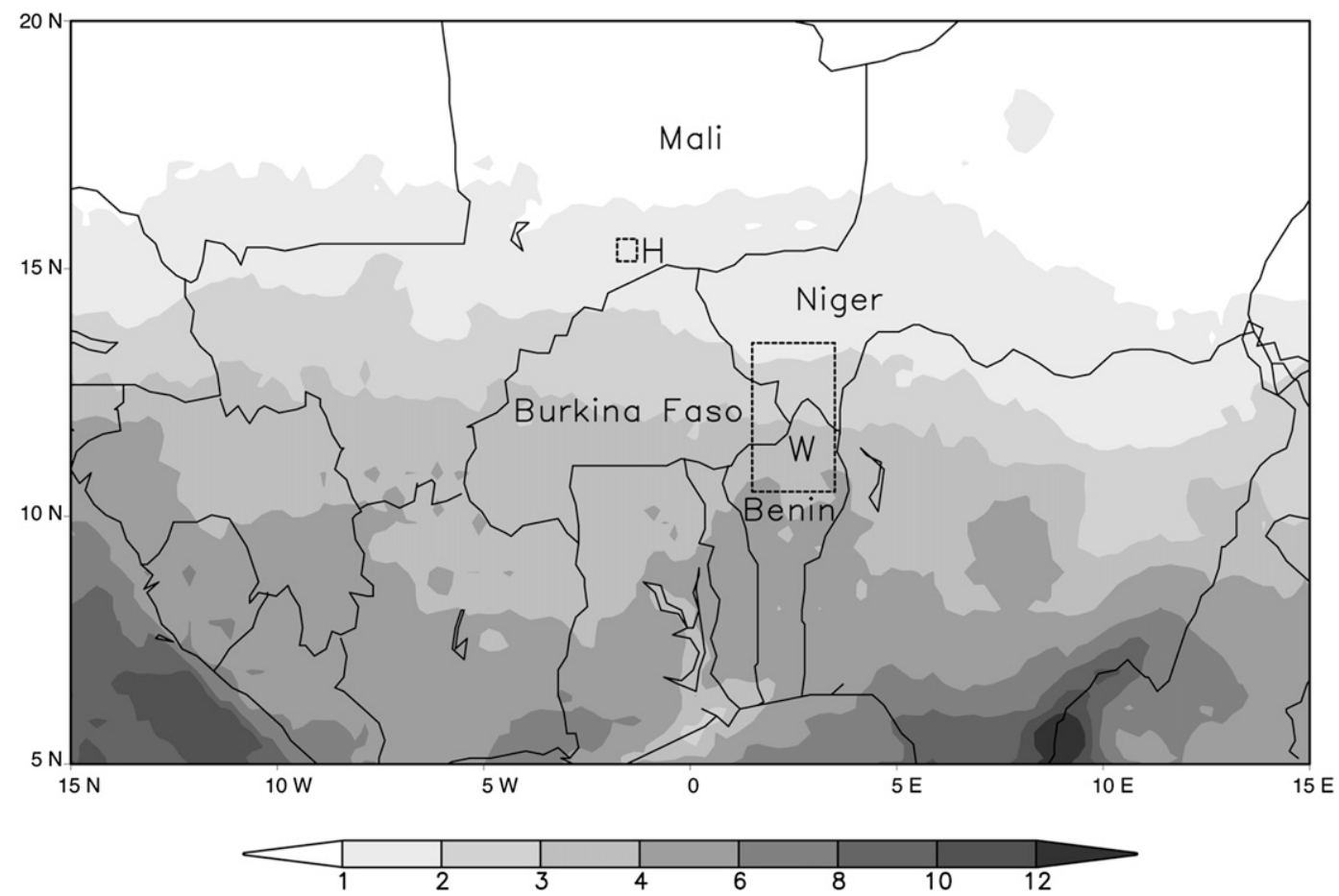

FIG. 1. Mean annual rainfall $\left(\mathrm{mm} \mathrm{day}^{-1}\right)$ shown as shaded contours for the period 2000-09 according to the TRMM 3B42 product. Location of the study areas, Hombori $(\mathrm{H})$ and Parc W (W) are shown within the dashed square.

simulated by this LSM compared to what is observed from space.

\section{Method}

\section{a. Study area}

In this paper we examine time series of LST under a range of land cover and climate conditions within the Sahel (Fig. 1). This study focuses on two mesoscale regions of West Africa, the first in Mali and a second, larger region at the southern fringes of the Sahel, which intersects Burkina Faso, Niamey, and Benin. These areas have contrasting rainfall conditions, $350 \mathrm{~mm} \mathrm{yr}^{-1}$ rain at Hombori (Timouk et al. 2009) and $817 \mathrm{~mm} \mathrm{yr}^{-1}$ at Gaya (Le Barbe and Lebel 1997). These two regions have been selected as previous studies have indicated contrasting surface characteristics (i.e., bare soils versus grassland for Mali and forest versus grass and croplands for the southerly region).

In Mali, we study the Hombori mesoscale site defined within the AMMA project (further details in Mougin et al. 2009). This is $51 \times 48 \mathrm{~km}^{2}$ in extent $\left(15.61^{\circ}-15.15^{\circ} \mathrm{N}\right.$, $\left.1.74^{\circ}-1.32^{\circ} \mathrm{W}\right)$. Two further local sites $\left(3 \mathrm{~km}^{2}\right)$ were also selected from within the Hombori window, specifically, Hedgerit $\left(15.50^{\circ} \mathrm{N}, 1.40^{\circ} \mathrm{W}\right)$ and Agoufou $\left(15.34^{\circ} \mathrm{N}\right.$, $1.48^{\circ} \mathrm{W}$ ), which are classified by the Global Land Cover
2000 (GLC2000) land cover map (Bartholome and Belward 2006) as stony desert and grassland, respectively. The Hombori region is predominately characterized by grassland $(74 \%)$, with a smaller proportion of stony desert $(26 \%)$ in the northern section according to GLC2000. Based on eddy correlation flux data, Timouk et al. (2009) examined the sensitivity of the surface energy and water budget to land cover within the Hombori region. They found strong contrasts in behavior between the stony desert (Hedgerit) and nearby grassland (Agoufou) sites. At the grassland site, rainfall drained tens of centimeters down through the profile of sandy soil, with evapotranspiration and evaporation from near the soil surface the dominant soil water loss terms. At Hedgerit, the evaporative response to rainfall was short (a few hours), with much of the rain running off the areas of hard pan.

The second larger study area, $324 \times 225 \mathrm{~km}^{2}$, is centered on the Parc W at the border of Benin, Niger, and Burkina Faso and is referred to herein as Parc W (13.5 ${ }^{\circ}$ $\left.10.49^{\circ} \mathrm{N}, 3.52^{\circ}-1.48^{\circ} \mathrm{E}\right)$. This region is located farther south and can be described by three major vegetation types: croplands $(44 \%)$, forest $(38 \%)$, and grasslands $(17 \%)$. Around Parc W itself there is a sharp contrast between the protected forest land and cropped areas. This situation formed the basis of study by Garcia-Carreras et al. (2010), who identified an organized atmospheric 
response to the strong (weak) sensible heat fluxes from the crop (forest) during the wet season.

\section{b. Land surface temperature data}

LST data were obtained from the Land Surface Analysis Satellite Applications Facility (LandSAF) and were recorded by the geostationary Meteosat Second Generation (MSG) satellite, which carries the Spinning Enhanced Visible and Infrared Imager (SEVIRI) sensor onboard (Sobrino and Romaguera 2004). LST is derived from TOA brightness temperatures recorded by infrared channels at 10.8 and $12.0 \mu \mathrm{m}$, using the splitwindow method (Wan and Dozier 1996). LST errors have been shown to be less than $1.5 \mathrm{~K}$ (Sobrino and Romaguera 2004). Data are acquired at 15 -min time intervals from cloud-free pixels, with a spatial resolution of approximately $3 \mathrm{~km}$. Further cloud and dust screening was applied to the LST time series following Taylor et al. (2011). The focus of this study is on variability on time scales of days rather than hours. To produce a daily signal based on incomplete daytime data, a seasonal mean diurnal cycle was constructed for every pixel, and then a mean LST anomaly (LSTA) is computed from all cloud-free data between 0700 and 1700 UTC on a particular day. We use LST data acquired for the years 2006-09 covering the wet season period from 22 May to 10 October. After screening the datasets for cloud and dust contaminated pixels, the number of samples lost was not greater than $30 \%$ on average, from a possible 142 observations for both mesoscale regions. In 2007, $31 \%$ of the northern section of the Hombori window is missing because of lack of emissivity information. Consequently, these missing data in 2007 were omitted from all calculations.

\section{c. Spectral analysis}

A range of approaches exist that test for the presence of periodic components within a time series, though many require that the data are sampled at regular intervals without gaps. In contrast, time series derived from Earth observation (EO) data tend to be irregularly sampled because of data loss resulting from instrument failure or screening for pixel contamination by cloud and/or dust. One solution might be to gap-fill the time series using an interpolation technique; however, this can result in bias because of the suppression of highfrequency components (Schulz and Mudelsee 2002). Alternatively, a model may be used to estimate missing data points, using a sequential filtering algorithm such as a Kalman filter to update model forecasts when observations are available. However, this solution requires the necessary model meteorological forcing data and suitable model calibration. For scenarios where data are acquired at irregular intervals, the Lomb-Scargle (LS) method, which only evaluates the data at the sampled intervals, has been suggested as an appropriate solution (Scargle 1989; Lomb 1976) and will be adopted in this study because of gaps in the LST time series.

The LS method estimates the periodogram "power" $(P$; i.e., the squared average amplitude or equivalently the variance) that occurs at each frequency $(\omega)$ via the Lomb-Scargle transform. The occurrence of peaks in the periodogram indicates frequencies of significant periodicity. The LS periodogram is described in Press et al. (1992) for a given time series $y\left(t_{i}\right)$ for $i=1, \ldots, N$ for time intervals:

$$
\begin{aligned}
P(\omega)= & \frac{1}{2 \sigma^{2}}\left\{\frac{\left[\sum_{i}\left(y_{i}-\bar{y}\right) \cos \omega\left(t_{i}-\tau\right)\right]^{2}}{\sum_{i} \cos ^{2} \omega\left(t_{i}-\tau\right)}\right. \\
& \left.+\frac{\left[\sum_{i}\left(y_{i}-\bar{y}\right) \sin \omega\left(t_{i}-\tau\right)\right]^{2}}{\sum_{i} \sin ^{2} \omega\left(t_{i}-\tau\right)}\right\}
\end{aligned}
$$

where $\tau$ is an offset and $\sigma^{2}$ is the variance in $y\left(t_{i}\right)$.

When perfectly regularly spaced data are analyzed by the LS transform, the result is identical to a discrete Fourier transform. The spectral estimates (i.e., the values of the power spectrum) are obtained from the sine and cosine amplitudes of the periodogram (derived from the LS transform) by using the discrete Hanning spectral window (yielding eight degrees of freedom; Priestley 1979). Unfortunately, the LS transform introduces bias in the periodogram power values that relates to the exact spacing of the data (Schulz and Mudelsee 2002). In this work we adopt the correction algorithm of Schulz and Mudelsee (2002) to evaluate and correct the spectral bias caused by the irregular data spacing. This approach uses the average spectra of hundreds of realizations of first-order autoregressive (AR1) processes, which are obtained at a matching time step to the observed data.

\section{d. Land surface model}

In this study we assessed the ability of a land surface model, the Joint UK Land Environment Simulator (JULES; Best et al. 2011; Clark et al. 2011; Essery et al. 2003; Cox et al. 1999), to simulate realistic variations in LST and, hence, land-atmosphere fluxes. In particular, we focused on day-to-day variations associated with surface drying after rainfall. JULES (version 2.0) is the land surface scheme in the UK Met Office Unified Model and uses a tiled approach (broadleaf tree, needleleaf tree, C3 grass, C4 grass, shrub, urban, inland water, bare soil, 
and ice) to represent subgrid heterogeneity in the surface state and fluxes. When used offline from the Unified Model, JULES is forced with time-varying boundary conditions of surface downward longwave and shortwave radiation and near-surface air temperature, humidity, pressure, wind speed, and precipitation.

Simulation runs in this study used forcing from ALMIP (Boone et al. 2009), specifically, the so-called ALMIP Experiment 3 forcing conditions for the single year of 2006. These comprise wind speed, air temperature, humidity, and pressure from the European Centre for Medium-Range Weather Forecasts (ECMWF) forecast model, downward longwave and shortwave radiation from the LandSAF, and precipitation from the Tropical Rainfall Measuring Mission (TRMM). Precipitation data at the coarser ALMIP scale were replaced by the $0.1^{\circ}$ Estimation of Precipitation by Satellite, second generation (EPSAT-SG) product (Chopin et al. 2005) during the months that EPSAT-EG data were available (June-September). Meteorological forcing data, with the exception of precipitation rate, were interpolated from a 3-h to a 30-min time step using the mean preserving method of Sheng and Zwiers (1998). The forcing data were then linearly interpolated in space from the ALMIP grid $\left(0.5^{\circ} ; \sim 50 \mathrm{~km}\right.$ in this region) onto the finer $(\sim 3 \mathrm{~km})$ SEVIRI grid for model runs. The model was spun up over 10 iterations of the complete 2001-08 ALMIP period, that is, 80 years of model integration in total. Each experimental simulation was initialized using the mean of the final ten 1 January states of that integration, following Rodell et al. (2005).

The tile fractions used in JULES were derived from the ECOCLIMAP surface cover product (Masson et al. 2003 ) and aggregated to the $\sim 3 \mathrm{~km}$ SEVIRI pixel scale. Seasonally varying phenology is represented by temporal interpolation of leaf area index (LAI) and canopy height from 10-day values to the 30-min model time step. Soil albedo was derived from 5-km Moderate Resolution Imaging Spectroradiometer (MODIS) observations (Houldcroft et al. 2009). Soil thermal and hydraulic parameters were derived from the Food and Agriculture Organization (FAO) database of texture classes (FAO 2003) using the pedotransfer functions of Cosby et al. (1984).

EO-derived LST will contain differing assumptions to those of the JULES-estimated LST, predominantly related to assumed vegetation cover and surface emissivity; consequently, modeled LSTs will show some divergence from satellite-derived LSTs in terms of the absolute magnitude of the values. To match the temporal variability of the EO LST with the modeled LST, modeled LST was screened such that 1) the mean diurnal cycle was removed, leaving a daily anomaly and
2) if a data point in the EO data was identified as being contaminated by dust and/or cloud, the matching temporal data point in the modeled LST time series was also removed.

\section{Capturing the surface response to rain at the site level}

The aim of this analysis is to explore how the surface energy balance over different land covers responds to rainfall focusing specifically at two mesoscale regions of West Africa. The details of this response are critical as it influences space-time variability in the planetary boundary layer (PBL) and thereby the initiation and propagation of mesoscale convective systems (e.g., Taylor et al. 2011). Observations have also shown that once a grass layer has developed in response to early rains, daily fluctuations in the partition of surface fluxes become suppressed, in turn affecting the buildup of convective instability over the course of the diurnal cycle (Kohler et al. 2010).

Figure 2 illustrates the seasonal evolution of the LST and rainfall over the summer months across the Sahel region for two years, based on 16-day data averaged between $10^{\circ} \mathrm{W}$ and $10^{\circ} \mathrm{E}$. High values of LST during May and early June give way to cooler conditions in July and August as the rainband advances northward. The change in LST is driven by the availability of soil water for evapotranspiration and the associated development of the vegetation. When the rains cease the LST rises again. The sensitivity of LST to rainfall on these spatial scales is evident when comparing Figs. $2 \mathrm{a}$ and $2 \mathrm{~b}$. The monsoon rains penetrate approximately $2^{\circ}$ farther northward in July and August 2007 compared to 2008, inducing lower LSTs in July and August 2007. When the 2007 rainy season ended rather abruptly, Sahelian LSTs rose sharply, in contrast to 2008.

We have computed the sensitivity of LST to antecedent rainfall at different latitudes using estimates from the TRMM 3B42 precipitation product, available at a resolution of $0.25^{\circ}$. The LSTA data were averaged onto the same grid and linear correlations between LSTA and rainfall on the previous day performed for each day of the season, exploiting all eighty $0.25^{\circ}$ grid boxes in each latitude band and each of the four years. The sensitivity of the LST to rainfall for two longitudinal bands centered on the two mesoscale study areas, as shown in Fig. 3a. Both longitudinal bands demonstrate a statistically significant lagged correlation with rainfall $\left(r=-0.24\right.$ and $r=-0.18, p<0.05$, for $15.4^{\circ}$ and $11.4^{\circ} \mathrm{N}$, respectively); that is, it rains and the following day there is a cooling in the surface temperature. The regions show similar patterns of behavior whereby early seasonal LST 
(a)

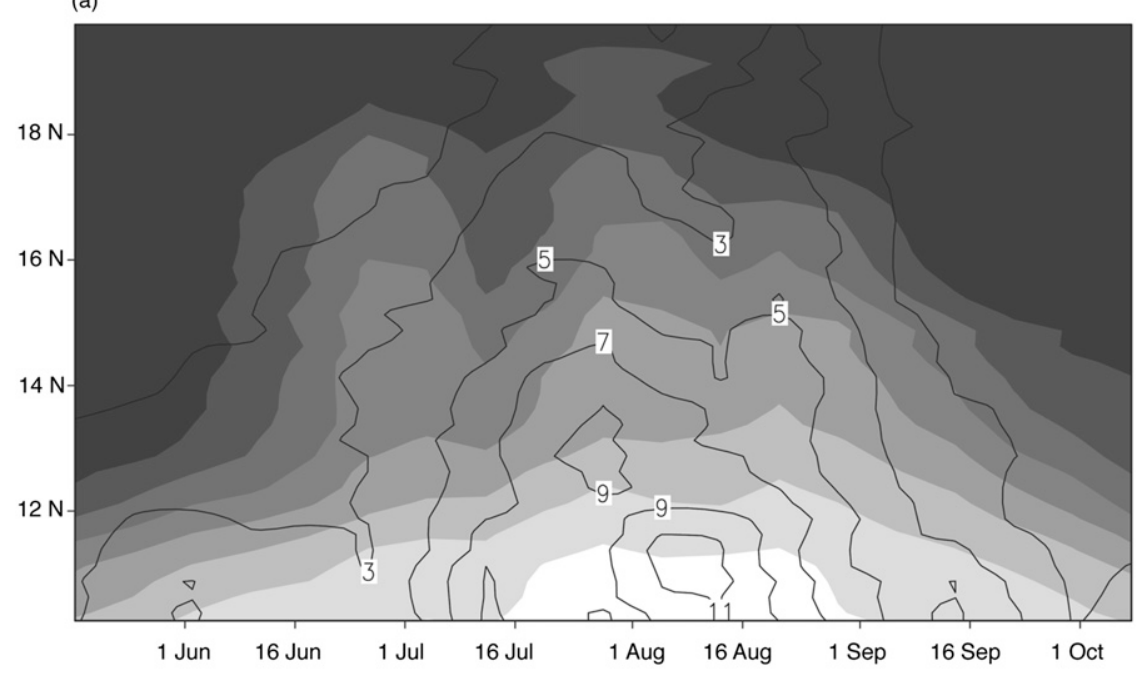

(b)

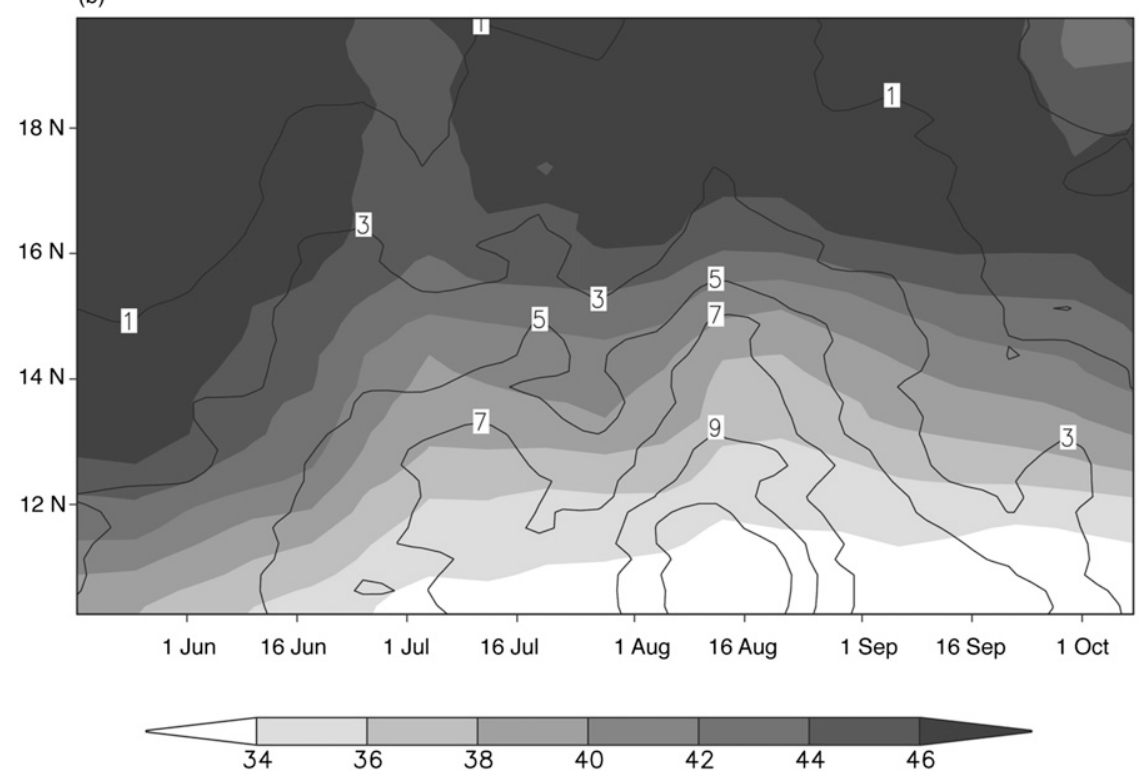

FIG. 2. Time-latitude diagram depicting the evolution of the African monsoon for the years (a) 2007 and (b) 2008. Data are averaged from $10^{\circ} \mathrm{W}$ to $10^{\circ} \mathrm{E}$ on a 16 -day time step, where shading indicates LST $\left({ }^{\circ} \mathrm{C}\right)$ and the contours show rainfall $\left(\mathrm{mm} \mathrm{day}^{-1}\right)$ from the TRMM 3 B42 product.

is highly sensitive to rainfall events. As the season progresses and vegetation cover increases (Fig. 3b), this sensitivity is reduced, consistent with field observations (Kohler et al. 2010). The more southerly region loses its LST sensitivity earlier in the seasons and is subsequently at least $0.3^{\circ} \mathrm{Cmm}^{-1}$ less sensitive than at $15.4^{\circ} \mathrm{N}$. This response can be attributed first to increased vegetation greenup in the southern band and second to an increased frequency of rainfall events. The low correlation coefficients quoted above are likely to be due to a combination of factors. At the space and time scale analyzed, the rainfall amounts are subject to large errors, while the choice of a single 24-h averaging period is an oversimplification — events outside of this period will also influence surface fluxes. Further variability in LSTA is likely due to day-to-day variations in wind speed and surface radiation (affected by misdiagnosed cloud and dust), as well as random errors in the LST product.

We now examine the LST variability in detail at the most northerly site. Outside of the rainy season little or no green vegetation growth takes place across the Hombori mesoscale region. The impact of the short rainy season on vegetation growth for the two sites is shown in Fig. 4a for a single year using the satellitederived normalized difference vegetation index (NDVI). Both sites show similar magnitudes in NDVI until the 


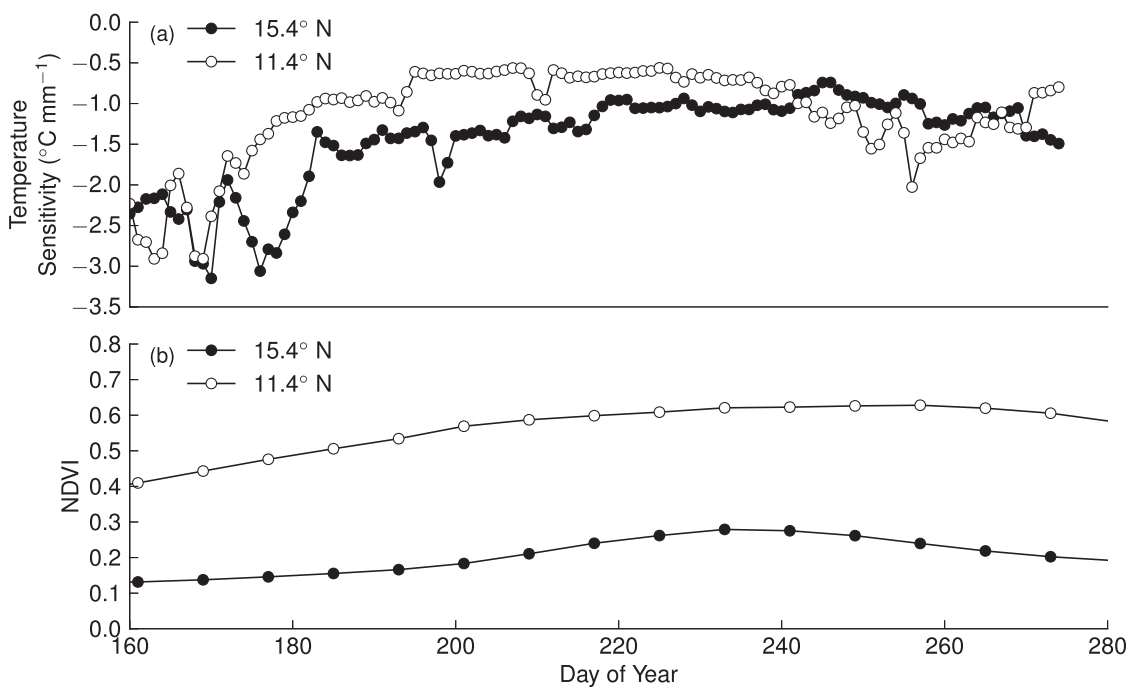

FIG. 3. Sensitivity of the LST to rainfall at $11.4^{\circ}$ and $15.4^{\circ} \mathrm{N}$ based on data between $10^{\circ} \mathrm{W}$ and $10^{\circ} \mathrm{E}$ for the years (a) 2006-09 and (b) 9-yr mean MODIS NDVI.

onset of the rains (days of year $>150$ ), when the Agoufou grassland site shows a rapid greenup $(\sim 0.3$ NDVI units $)$ and dieback. In contrast, the Hedgerit site (stony desert) shows only a minor indication of a vegetation response to rainfall (i.e., greenup). Figure $4 \mathrm{~b}$ shows the LST observed for the two sites and the TRMM rainfall from the corresponding $0.25^{\circ}$ pixel. Both sites show a similar seasonal transition in LST, but with notable differences in the magnitude of the LST values; this coincides with the period of greenup (days of year 150-270). Agoufou has a smoother response to rainfall events and remains $0.7^{\circ} \mathrm{C}$ cooler throughout the rainy season, whereas the Hedgerit site has a noisier profile. The increased LST variability on a daily time scale at Hedgerit is consistent
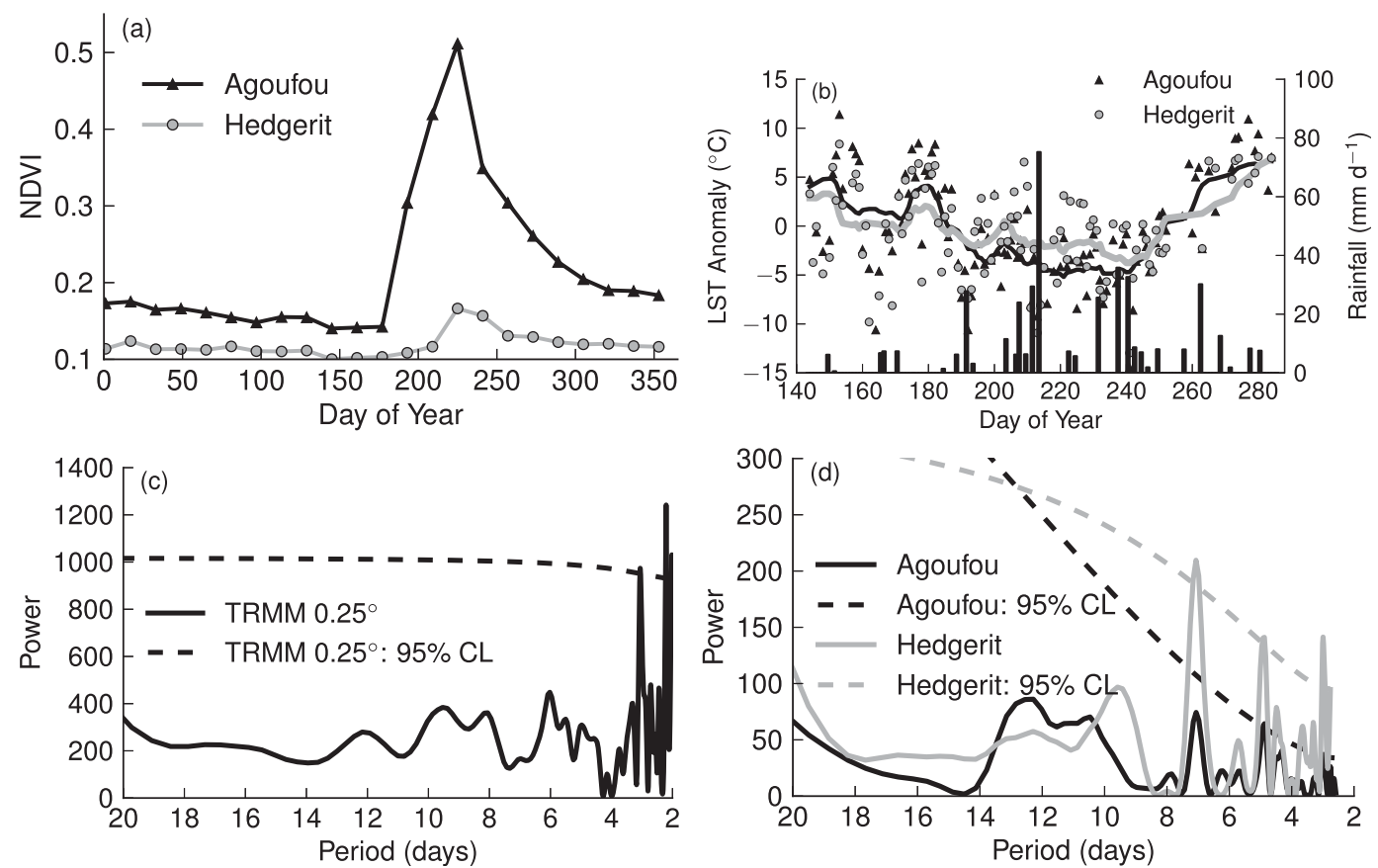

FIG. 4. Comparison of the observed (a) MODIS NDVI, (b) MSG LSTA and TRMM rainfall, and their associated spectra of (c) TRMM rainfall and (d) LST for two sites in the Hombori mesoscale window for the year 2006. Note that the frequency axis of the spectra plots in (c) and (d) have been truncated to show short time scale responses, that is, from 20 days to the Nyquist frequency. 
(a)

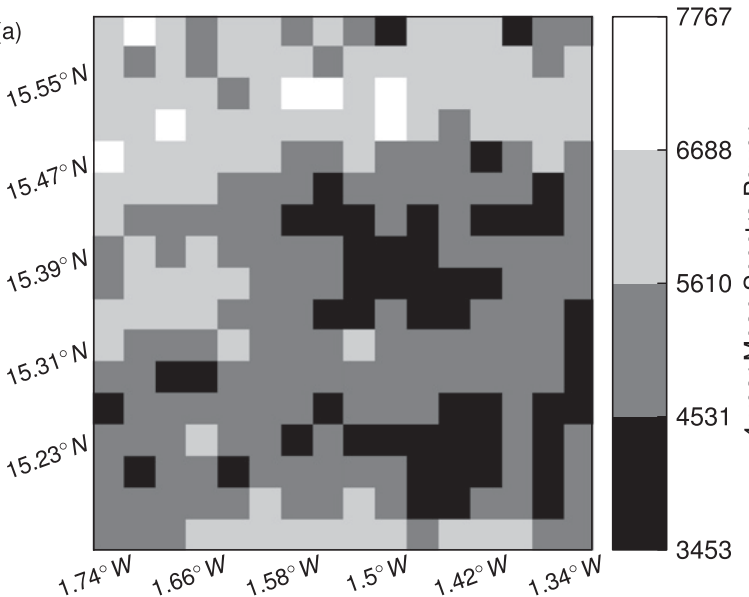

(b)

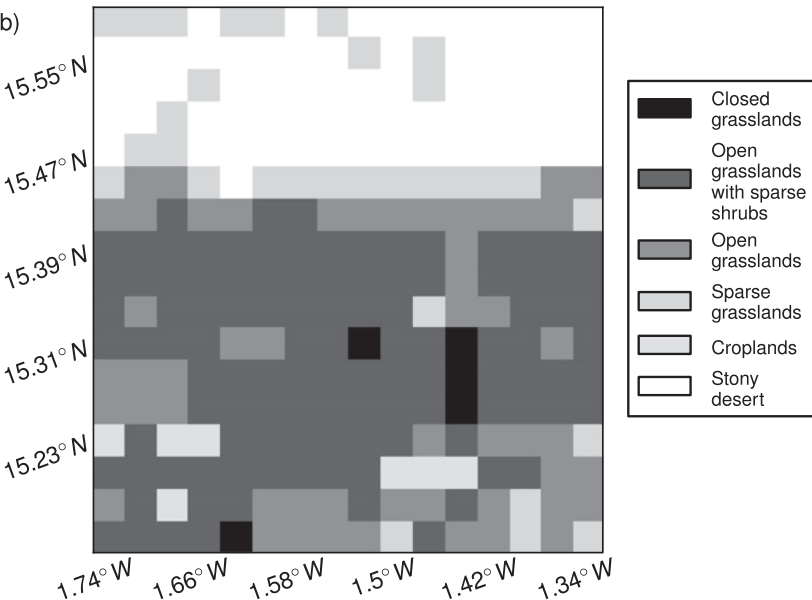

FIG. 5. Spectral comparison of the 2-5-day variance of the EO LST for the (a) Hombori mesoscale and the (b) corresponding land cover map.

with in situ observations (Timouk et al. 2009), which indicate a rapid drying of the surface after rain because of runoff and minor infiltration, and, hence, large variations in surface temperature. The rapid greenup of the grassland (Agoufou) site changes the vegetation structure and therefore the aerodynamic resistance with the effect of decreasing LST there. Once established, the grasses can access water in the root zone, allowing the plants to transpire during dry spells of a few days. In contrast, the stony desert site (Hedgerit) without such a water regulation mechanism and impediments to turbulence, will freely evaporate surface water and, once dry, warm up more rapidly after rainfall.

Figures $4 \mathrm{c}$ and $4 \mathrm{~d}$ show the spectral analysis for the TRMM rainfall and the MSG LST time series. The dominant periodicities in the rainfall data (Fig. 4c) occur on time scales of less than 5 days, consistent with the passage of mesoscale convective systems, which are weakly associated with African easterly waves. Statistically significant periodicities occur at 2.2 and 3.1 days, with another significant peak also found at 24.9 days (not shown). Likewise, the spectra for the LST data (Fig. 4d), have a similar shape (peaks at similar intervals), with greatest variability at shorter periodicities ( $<10$ days). Statistically significant peaks for the Agoufou site occur at 2.7, 2.9, and 4.9 days and 2.9, 4.9, and 7.1 days at the Hedgerit site.

One might expect that sites with such contrasting land covers and associated water balances as Hedgerit and Agoufou (Timouk et al. 2009) would exhibit different periodicities in the LST time series. However, the differences in periodicity between the sites Agoufou and Hedgerit are negligible in our analysis, and there is not a single dominant periodicity (Fig. 4d). It appears that what dominates the periodicity of spectral peaks is the sequencing of rain events. Spatial variability in rain is very marked in the Sahel, even at this scale of $15 \mathrm{~km}$ (Taylor et al. 1997), and may obscure more subtle differences in periodicity imposed by the land surface. In addition, missing data (due to cloud and dust) and the quality (e.g., coarseness of the data, $\sim 3 \mathrm{~km}$ ) of the LST data presents problems with this spectral approach. On the other hand, while we are unable to distinguish differences in the occurrence of statistically significant periodicities, there is a clear difference between the two sites in terms of total variance in the 2-5-day band. Figure $4 \mathrm{~d}$ indicates the response to the rain is $59 \%$ stronger at the Hedgerit site compared to the Agoufou site, consistent with the physical mechanisms outlined above.

\section{Quantifying the response to rainfall at the mesocale}

Detailed spectral analysis results at the individual pixel scale suggested we could not detect peaks at different frequencies for different land covers. However, by examining an increased number of pixels within the Hombori mesoscale domain, we seek to extract a stronger spatially averaged signal, in particular, illustrating the different LST responses to rainfall between land cover types. The land cover map (GLC2000) illustrates two broad cover types, stony desert and grassland (Fig. 5b). Figure 5a shows the corresponding average 2-5-day variance (squared average amplitude) for the same area depicted in the land cover map. Visual inspection suggests areas of stony desert across the northern regions are associated with higher variance, consistent with analysis of the two field sites (Fig. 4). Within this domain, the difference in mean power between these two land cover classes is 1006 .

Figure 6 examines the periodicity and power of statistically significant peaks as a function of land cover 

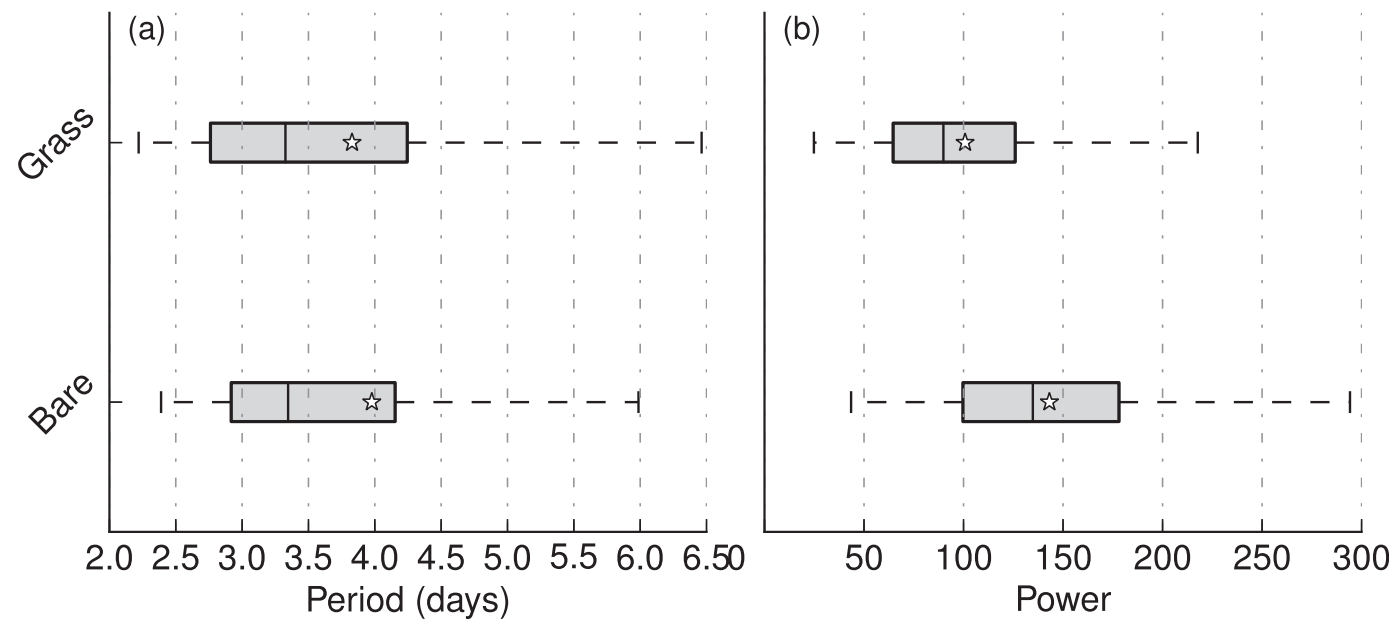

FIG. 6. Boxplot of the median (vertical line) and mean (star) (a) periodicity and (b) power of statistically significant spectral peaks from the EO LST data over the period of 2006-09, classified by land cover type (grass and bare). The ends of the box show the lower (25th) and upper (75th) quartiles. The horizontal whiskers show the full range of the data.

within the Hombori domain. For each pixel, we recorded every statistically significant peak and its associated power and then grouped these data by land cover type. For this analysis it is assumed all the grass and crop classes are a single grass land cover. Our previous analysis (Fig. 4) has indicated the period of response to rainfall is dominated by a short-term response, and so here we focus on time intervals $<10$ days. We used Cohen's $d$ to quantify the difference between the mean of two groups divided by the pooled standard deviation of the data. Differences between groups are measured in terms of the number of standard deviations: it is typically assumed that $d$ of 0.2 shows a small, 0.5 a medium, and 0.8 a large effect size. Figure $6 a$ indicates that $\sim 75 \%$ (bare) and $\sim 85 \%$ (grass) of statistical significant spectral peaks match the dominant response interval of the rainfall signal, that is, $<5$ days. However, there is no clear difference in periodicity of the statistical significant peaks [bare pixels (days) mean $(\mu)=3.83$, standard deviation $(\sigma)=1.55$ versus grass pixels (days), $\mu=3.98$, $\sigma=1.77$, and $d=0.09]$. As with our earlier analysis at the single pixel scale, the spectral approach for the Hombori mesoscale area cannot distinguish distinct periodicities between surface types. However, as Fig. $6 \mathrm{~b}$ shows, there are clear differences in terms of a higher power response for bare areas compared to grassland areas $(d=0.87)$.

Here we try an alternative, more empirical approach to analyzing the time series. To get a better understanding of LST variability on these short time scales, and its sensitivity to land cover, we have composited the time series for individual pixels based on a drop in LST from one day to the next exceeding a certain threshold $\left(3^{\circ}, 5^{\circ}\right.$, or $\left.7^{\circ} \mathrm{C}\right)$. We assume this drop in LST occurs in association with a local rain event. For individual events we cannot rule out other causes for the drop in LST (e.g., aerosol contamination), but by averaging over many such events we hope to suppress the impact of misdiagnosis
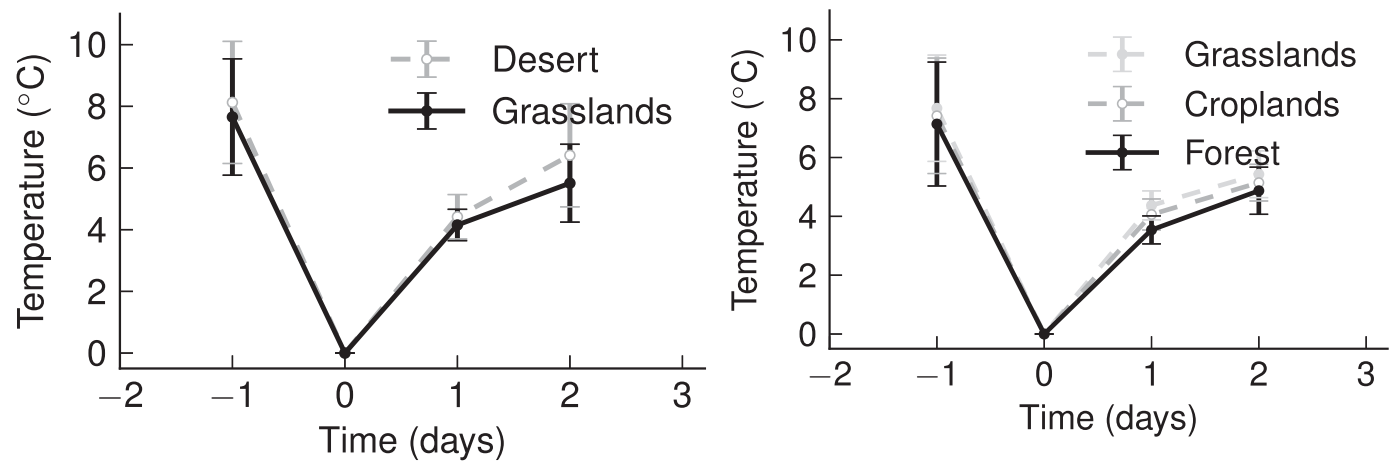

FIG. 7. Composite of the 4-yr (2006-09) drying cycles following rainfall (threshold $=5^{\circ} \mathrm{C}$; time $=0$ ), classified by land cover type for the (left) Hombori and (right) Parc W mesoscale windows. 

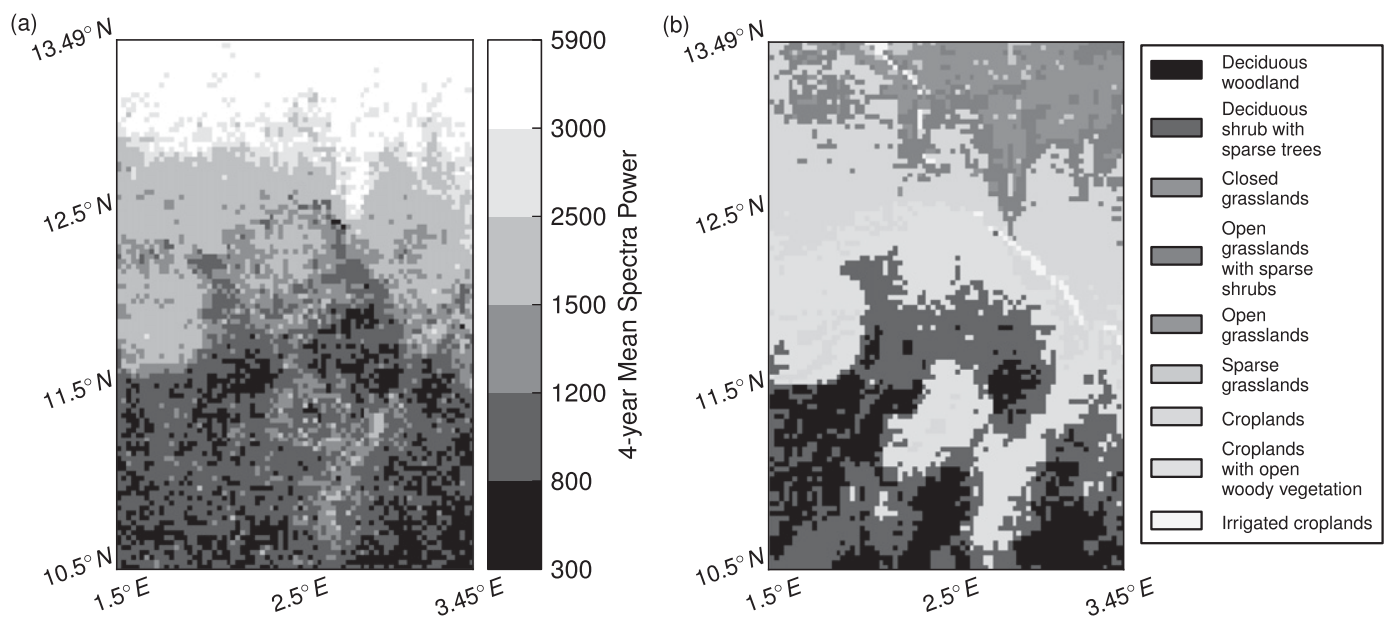

FIG. 8. Spectral comparison of the 2-5-day variance of the EO LST for (a) the Parc W mesoscale and (b) the corresponding land cover map.

of rain. Figure 7 (left) shows a 4-yr composite of the drying cycle following rain for the Hombori region. The desert pixels warm more quickly and are approximately $0.3^{\circ} \mathrm{C}$ warmer than the grassland site the day after rainfall $(d=0.11)$, and they are $1^{\circ} \mathrm{C}$ warmer by the second day $(d=0.22)$. The differences in warming patterns between land cover types in the days after rainfall were found to be consistent irrespective of chosen threshold: $3^{\circ}, 5^{\circ}$, or $7^{\circ} \mathrm{C}$ (not shown). The differences in the composite time series between land cover types can be interpreted in terms of processes described from in situ observations in this region (Timouk et al. 2009). The stony desert exhibits a strong LST decrease and more rapid warming on the first day following a rainfall event, consistent with a short (hours) period of high evaporation. Over the sandy soils of the grassland site, there is a slower drying cycle. Evidently, the more empirical approach is able to detect clear differences between surface types, in both the amplitude and the recovery rate after rainfall.

We now perform a similar set of analyses exploring the sensitivity of LST variability to land cover in a wetter, more densely vegetated region of West Africa. The influence of land cover on spectral amplitude of variability ( $<5$ days) is readily apparent for the Parc W mesoscale region shown in Fig. 8. The 4-yr average, 2-5-day variance signal can largely be categorized into three classes, which correspond with the grassland, crop, and forest areas, shown in Fig. 8b. Forested pixels produced the weakest 4 -yr-average, $<5$-day variance response $(\langle P\rangle)$ of $928.9 \pm 431.1(\mu \pm \sigma)$, followed by the area of cropland $(\langle P\rangle=1756.9 \pm 892.7)$, whereas the strongest response was recorded from the grassland region $(\langle P\rangle=$ $3481.2 \pm 1289.8)$.

Figure 9a indicates the majority of statistically significant spectral peaks for all land cover types occur
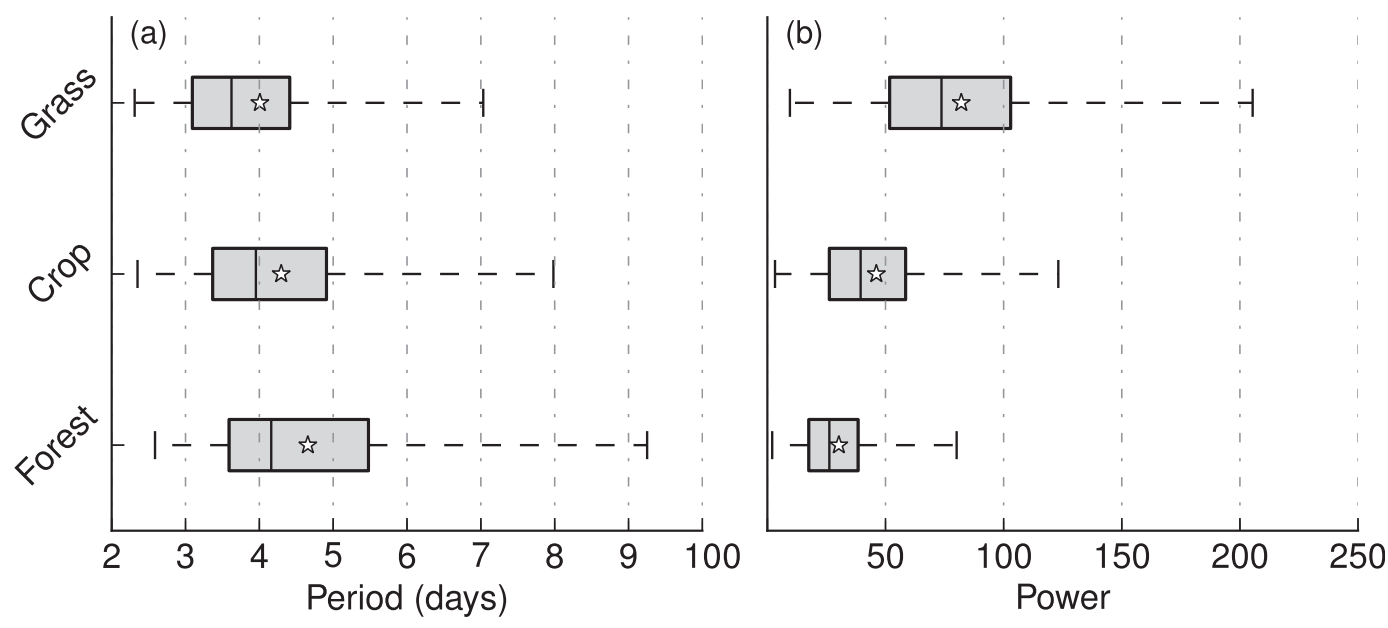

FIG. 9. As in Fig. 6, but for grass, crop, and forest. 

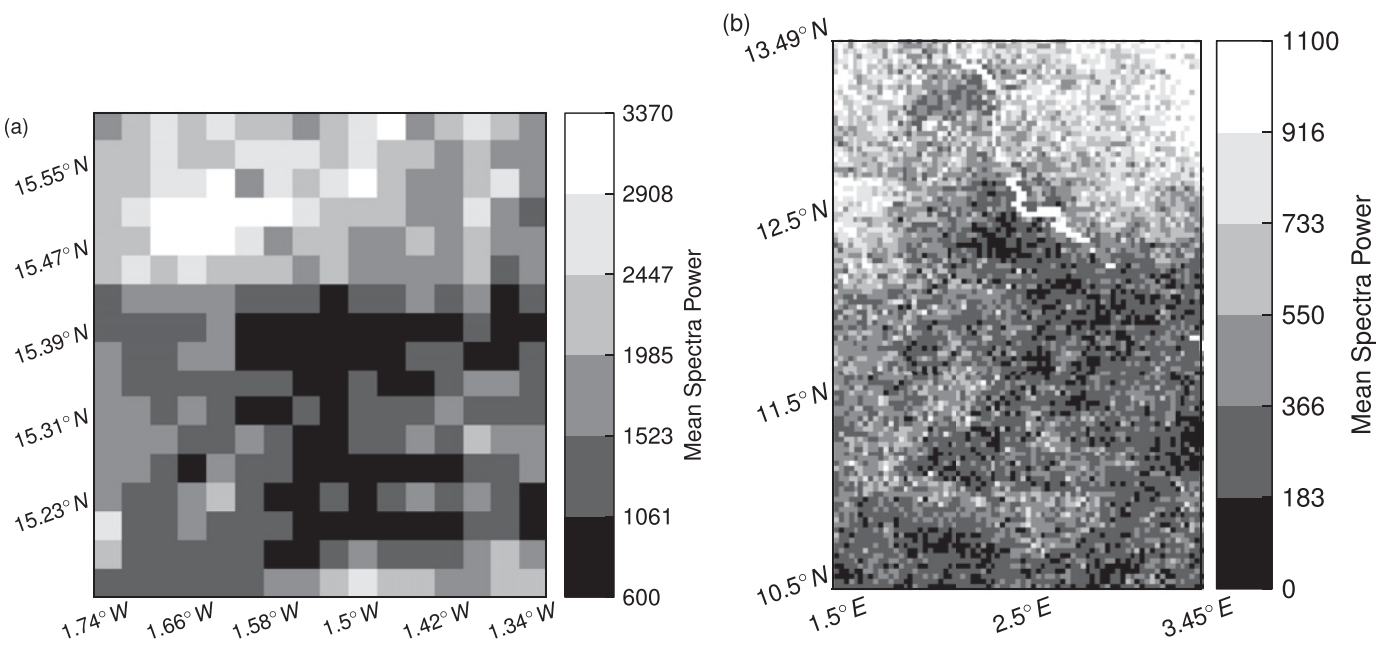

FIG. 10. Spectral 2-5-day variance of the JULES LST for (a) the Hombori region and (b) the Parc W mesoscale window. All data shown are from 2006 and have been screened so that identical time periods have been analyzed to the EO data, therefore accounting for the influence of cloud and/or dust. Data shown in (b) has been clipped, with the maximum range extending to 2198.5 . This affects $1.2 \%$ of the data.

between 3 and 5 days. For periodicities of less than 10 days, there is a small shift toward longer time scale periodicities in forested pixels $(\mu=4.66, \sigma=1.45)$ compared to both grassland $(\mu=4.0, \sigma=1.31, d=0.46)$ and croplands $(\mu=4.30, \sigma=1.34, d=0.26)$. Following Cohen (1988), these values indicate that $\sim 33 \%$ and $\sim 18 \%$ of the statistical significant periodicities do not overlap with grassland and cropland pixels, respectively. Here, unlike Hombori, we are able to discern differences in terms of the statistical significant periodicities. While these overall differences, $>0.5$ days, might not appear large, this is the mean difference and variability in this periodicity spatially within and between surface types will result in different feedbacks to the PBL. Similar to the analysis of the Hombori region, there are distinct differences between the power of the responses (magnitude) for different land cover types (Fig. 9b). The magnitude of responses for forested pixels in the Parc W region do not overlap grassland and cropland distributions for $\sim 75 \%(d=1.78)$ and $\sim 38 \%$, respectively $(d=$ $0.65)$. This confirms the sizeable differences in the power responses between land cover types. Similar results from repeated analysis over smaller regions showed that differences in the frequency of spectral peaks between land cover classes were not due to the relatively large domain size (and associated within domain meteorological forcing). Instead, we interpret the differences as having a biophysical basis. Forests have stronger controls on water transfer to the atmosphere, through their leaf stomatal opening as well as deeper rooting systems. Differences in the periodicity for forested regions, that is, a greater number at longer periodicities, indicate that the forest areas are better able to maintain evapotranspiration during dry spells. This interpretation is supported by the Parc W composited drying curves (Fig. 7 , right), where the forest sites remains $0.5^{\circ}-0.9^{\circ} \mathrm{C}$ and $0.3^{\circ}-0.7^{\circ} \mathrm{C}$ cooler than the other land cover types for the first and second days following rainfall, respectively. Through analysis of the LST data, we are able to establish differing responses of the land surface to rainfall; furthermore, this can be attributed directly to land surface variability.

\section{Land surface model analysis}

We now apply the methodology of spectral analysis used with the EO data to output from the JULES LSM as forced with high-resolution meteorological data. This is done for 2006, the only year of overlap between the forcing and LST data. Figure 10 shows maps of 2-5-day variance for a single year, 2006 (when we had overlapping forcing and EO data), from JULES for Hombori and Parc W. For the Hombori region, shown in Fig. 10a, the spatial structure is similar in model and observation for 2006 (not shown) with a correlation of 0.71 between the two patterns. Furthermore, the LST variability resembles the land cover classes in Fig. 5b, with increased variability over stony desert. The prescribed JULES vegetation cover in this region is similar to the GLC2000 map, and it appears to be the dominant cause of the good model-observation agreement.

Analysis of the simulated LST variability for 2006 for the Parc W domain (Fig. 10b) shows good modelobservation agreement with the observed 2006 variance 
$(r=0.61)$. The impression of three broad land cover types is still discernible from a single-years EO analysis, if not an exact mapping (not shown). However, the JULES output does not appear to show any spatial organization relating to the GLC2000 land cover classes (Fig. 8b). This may be linked to the simplified prescription of land cover in the JULES simulation, with largely forest in the south and grasses in the north (JULES has no crop class).

For both regions, the total power of the JULES spectral analysis is noticeably lower, the maximum power values are 2.3 and 5.4 times smaller for Hombori and Parc W, respectively, than the EO analysis. By adding random Gaussian noise to the JULES LST data, it was determined that at least part of this difference $(\sim 7 \%)$ can be attributed to noise in the observations derived from EO, where errors may reach $1.5 \mathrm{~K}$ (Sobrino and Romaguera 2004). Another potentially important contribution to lack of variability in the model is the meteorological forcing. In particular, compared to a time series of observations at the scale of an MSG pixel $\left(\sim 10 \mathrm{~km}^{2}\right)$, the rainfall forcing at a resolution $\sim 800 \mathrm{~km}^{2}$ will tend to smear out rain in space and time. This low power, however, is also consistent with a previous analysis of $0.5^{\circ}$ ALMIP simulations (de Rosnay et al. 2009) over a wider West Africa domain. In that analysis, JULES exhibited only $67 \%$ of the observed variance in C-band brightness temperature, the weakest of the eight models compared, although this was sensitive to assumptions in the microwave forward model. Analysis of intraseasonal LST biases in the simulations sheds some light on the origins of the low variability in JULES. During the first 50 days of the time series, the JULES LST has a warm bias of $5.3^{\circ}$ and $4.4^{\circ} \mathrm{C}$ on average for the first 50 days of the time series compared to the EO LST for the Hombori and Parc $\mathrm{W}$ regions, respectively (Fig. 11). It is evident in Fig. 11 that this coincides with relatively weak day-to-day variability in simulated LST compared to the EO data. This suggests that the modeled LST is not sufficiently sensitive to any early season (May, June) rainfall events, when the drop in temperature induced by rainfall is large (Fig. 3a). This may be linked to the use in JULES of soil moisture in a $10-\mathrm{cm}$ thick layer to determine evaporation direct from the soil.

To gain a better understanding of the likely origins of our model-observation differences in LST variability over the two domains, we performed a series of sensitivity simulations. The first objective was to identify the relative roles of vegetation and soil properties in generating spatial variability in the simulations. These runs were done in separate simulations where, rather than use the standard soil and vegetation

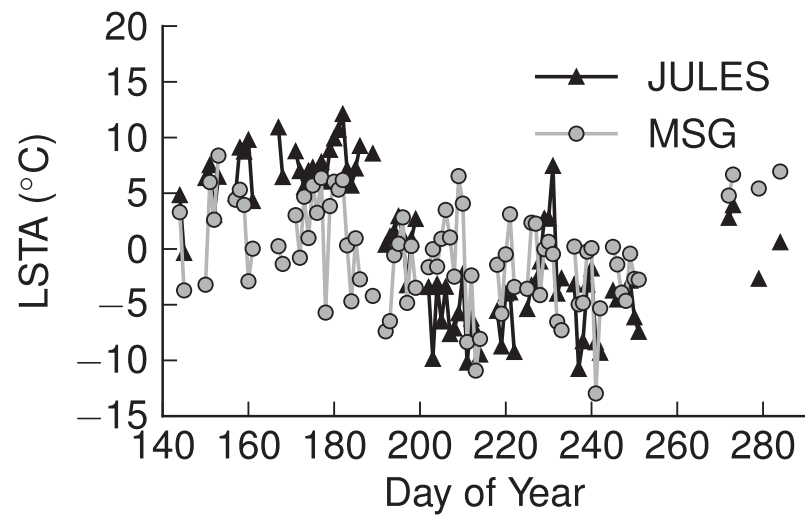

FIG. 11. LST bias between JULES modeled data and satellite derived for the Hedgerit site.

maps, uniform soil properties and/or vegetation cover were prescribed. We then examined the impact of key vegetation parameters (roughness length for heat and root depth) on the LST variance. These simulations are summarized in Table 1.

\section{a. Hombori}

We first tested the sensitivity of modeled LST variance to the prescription of the vegetation cover and soil. Imposing a uniform grass (bare soil) surface decreased the variance by $41 \%$, while imposing uniform bare soil increased the variance by $39 \%$. On the other hand, imposing uniform soil properties had only minor additional impacts on the variance. The lack of sensitivity to soil properties implies that the model is able to capture well the mesoscale structure in LST variance because of the land cover map rather than the soil map. In reality, the highly contrasting behaviors of the Agoufou and Hedgerit sites are primarily due to soil characteristics (freely draining at the grassland site, lateral flows dominant at the stony desert site), which determine what vegetation can develop there. Evidently, soil parameters derived from the FAO global soil map are unable to capture this behavior. We then assessed the relative importance of two key vegetation properties in determining LST variance, the roughness length and the root depth. Reducing the vegetation roughness by an order of magnitude has a large impact on the 2-5-day variance $(131 \%)$ and improves the agreement with the LST map derived from EO data $\left(r^{2}=0.91\right)$. This increased variance stems from the increased aerodynamic resistance that raises the LST when the surface is dry. Reducing the rooting depth that JULES grass has access to from 0.5 to $0.01 \mathrm{~m}$ (scenario 4) also has a significant effect and increases the mean variance by $91 \%$ compared to the control. Given the observed-modeled mismatch in variance, these results suggest that the 
TABLE 1. A summary of the sensitivities of the 2-5-day variance in the modeled LST spectral analysis. Mean percent change is calculated as the mean of all the percentage changes for every pixel (control vs sensitivity experiment). All model runs have varying meteorology forcing. Model simulations with varying soil and/or vegetation indicate simulations with spatial varying properties between pixels; $r^{2}$ is the coefficient of determination between the control run and the various scenarios.

\begin{tabular}{|c|c|c|c|c|}
\hline & Range & $\mu \pm \sigma$ & $\begin{array}{l}\text { Mean \% change } \\
\text { in 2-5-day variance }\end{array}$ & $r^{2}$ \\
\hline Hombori: Control run & $600-3370$ & $1660 \pm 613$ & N/A & N/A \\
\hline Scenario 1a: Uniform grass land cover, varying soil properties & $363-1935$ & $906 \pm 266$ & $-41 \%$ & 0.42 \\
\hline Scenario 1b: Uniform bare land cover, varying soil properties & $1260-3338$ & $2106 \pm 401$ & $39 \%$ & 0.49 \\
\hline Scenario 2: Varying vegetation, reduced vegetation roughness & $1590-6910$ & $3752 \pm 1277$ & $131 \%$ & 0.91 \\
\hline Scenario 3a: Uniform grass land cover, fixed soil properties & $346-1732$ & $782 \pm 258$ & $-49 \%$ & 0.52 \\
\hline Scenario 3b: Uniform bare land cover, fixed soil properties & $1260-3338$ & $2106 \pm 401$ & $39 \%$ & 0.49 \\
\hline Scenario 4: Varying vegetation, small rooting depth & $1594-4255$ & $2834 \pm 470$ & $91 \%$ & 0.33 \\
\hline Parc W: Control run & 0-2198 & $464 \pm 260$ & N/A & N/A \\
\hline Scenario 1a: Uniform forest land cover, varying soil properties & $60-1413$ & $494 \pm 182$ & $34 \%$ & 0.66 \\
\hline Scenario 1b: Uniform grass land cover, varying soil properties & $58-1894$ & $610 \pm 290$ & $51 \%$ & 0.83 \\
\hline Scenario 2: Varying vegetation, reduced vegetation roughness & $77-3872$ & $903 \pm 575$ & $107 \%$ & 0.88 \\
\hline Scenario 3: Uniform forest land cover, fixed soil properties & $56-1399$ & $482 \pm 175$ & $31 \%$ & 0.91 \\
\hline Scenario 4: Varying vegetation, reduced root depth for forest PFT & $48-2936$ & $694 \pm 457$ & $56 \%$ & 0.88 \\
\hline
\end{tabular}

model is not sensitive enough to temporal variations in root zone soil moisture, possibly linked to an overly large soil reservoir. In addition, the aerodynamic conductance (derived from the roughness length) may be too large.

\section{b. Parc $W$}

The LST variance for the Parc W simulation (Fig. 10b) does not capture the mesoscale structure evident in the observations, or indeed in the GLC2000 land cover map. From sensitivity runs we can infer only a limited influence of soil type on the simulated LST variability, as also found at Hombori. Varying the soil parameters has a negligible impact (3\% change) if the surface is covered in a uniform forest cover (difference between scenario 3 and 1). As for the Hombori domain, it is the vegetation that has a bigger impact on LST variance than soil. Imposing uniform grassland cover raises the variance by $51 \%$, whereas a uniform forest cover raises the variance by $34 \%$ (scenario 1a). Again, we tested the sensitivity of the variance to individual vegetation parameters. Decreasing the root zone water access for broadleaf tress from 3 to $0.5 \mathrm{~m}$ (scenario 4) increases the 2-5-day spectral variance $(56 \%)$ and improves the correspondence with the EO map $\left(r^{2}=0.88\right)$. However, the greatest change in spectral variance $(107 \%)$ is produced by reducing the roughness length of both grasses and forest pixels by an order of magnitude (scenario 2). This analysis confirms that the suppressed LST variance in JULES is likely linked to an overly large soil moisture reservoir and/or excessive roughness length for heat. However, neither of these adjustments increases the realism of the simulation when compared to the EO spectral map (visual inspection, not shown); rather, they highlight that the specification of vegetation fractions for this area are erroneous.

\section{Discussion and conclusions}

Understanding how the surface responds to rainfall in semiarid regions is a prerequisite for predicting how land cover change or soil moisture anomalies feed back on regional climate. We have demonstrated that LST data derived from EO, when combined with spectral analysis, are useful for quantifying the variability in the land surface response to meteorological forcing. We identified a negative correlation between LST and antecedent precipitation across the Sahelian region, highlighting that LST is most sensitive early in the growing season (Fig. 3). Focusing on two mesoscale regions, each containing contrasting surface properties, our analysis does not distinguish a single dominant periodicity in LST, but rather, a window of response $(<5$ days $)$ in which the surface temperature indicates a strong response to rainfall forcing (Figs. 4, 6). Based on 4 years of data, the influence of contrasting land surface properties is discernible. This is most clearly shown in Fig. 8, where the forest and grassland boundaries around Parc $\mathrm{W}$ are evident. Our analysis indicates that the variance of this rainfall signal (2-5 days), or strength of the response, varies strongly with land cover types. More densely vegetated areas, for example, forests, have the weakest response to rainfall, in contrast to bare regions, which show very high variance. These differences in response relate to both the amount of the initial surface cooling and the subsequent rate of the drying process following rainfall (Fig. 7). The physical characteristics of the surface 
govern these responses through the effects of stomatal control on the return of moisture to the atmosphere, aerodynamic resistance on evapotranspiration rates, runoff, drainage of the soil, and the depth of vegetation roots.

We found some evidence of different periodicities in the LST data stemming from the underlying land cover. We have shown through spectral analysis and a more empirical approach that there are longer periodicities in the forest area for the Parc W region (Fig. 6). For the Hombori region, no significant differences in time scales were detected using spectral analysis. However, the empirical approach identified that grassland pixels typically warm at a slower rate than desert pixels following rainfall (Fig. 7). As the number of days since a rainfall event increases ( $>2$ days), the bare soil has warmed by as much as $1^{\circ} \mathrm{C}$ more than the grassland. Furthermore, the mean amplitude of the response is 1.6 times greater in the bare regions compared to the grassland cover pixels. In the Parc $\mathrm{W}$ mesoscale region, grasslands have a response that is nearly 3 times larger than that of nearby forested areas. Dickinson et al. (1991) notes that short grasslands would characteristically have an order of magnitude lower aerodynamic resistance compared to that of a forest. These differences are critical, affecting water return to the atmosphere and, therefore, $\mathrm{PBL}$ development. Taken together, these results are consistent with in situ studies that show that areas of low vegetation cover increase the temporal variability in fluxes with potential impacts on atmosphere (Bagayoko et al. 2007; Mougin et al. 2009; Timouk et al. 2009).

The difference in variance between land cover types is a significant result and is certainly one that JULES has trouble replicating in our simulations. We found that JULES matched the observed spatial structure well for Hombori (Fig. 10a) because of the specification of vegetation cover. In contrast, for the Parc W region the model had poor discrimination between the vegetation cover present (Fig. 10b). Interestingly, we found that spatial variability in soil had a negligible impact on the modeled LST signal, even across an area where soil type is known to be a key driver in the surface energy balance (Mougin et al. 2009; Timouk et al. 2009). These results indicate that JULES LST day-to-day variability is too weak. Likely causes of this include unrealistically deep surface and root zone soil moisture reservoirs and an excessively large roughness length for heat. For both mesoscale regions, correctly determining the fractional cover of vegetation, the associated vegetation surface roughness, and the rooting depth is critical. Our results suggest that modeled responses to rainfall by JULES are particularly sensitive to these parameters.
Acknowledgments. This work was funded by the National Centre for Earth Observation.

\section{REFERENCES}

Anthes, R. A., 1984: Enhancement of convective precipitation by mesoscale variations in vegetative covering in semi-arid regions. J. Climate Appl. Meteor., 23, 541-554.

Bagayoko, F., S. Yonkeu, J. Elbers, and N. van de Giesen, 2007: Energy partitioning over the West African savanna: Multiyear evaporation and surface conductance measurements in eastern Burkina Faso. J. Hydrol., 334, 545-559.

Bartholome, E. M., and A. S. Belward, 2006: GLC2000: A new approach to global land cover mapping from earth observation data. Int. J. Remote Sens., 26, 1959-1977.

Best, M. J., and Coauthors, 2011: The Joint UK Land Environment Simulator (JULES), model description. Part 1: Energy and water fluxes. Geosci. Model Dev., 4, 677-699.

Boone, A., and Coauthors, 2009a: The AMMA Land Surface Model Intercomparison Project (ALMIP). Bull. Amer. Meteor. Soc., 90, 1865-1880.

_ I. Poccard-Leclercq, Y. Xue, J. Feng, and P. Rosnay, 2010: Evaluation of the WAMME model surface fluxes using results from the AMMA land-surface model intercomparison project. Climate Dyn., 35, 127-142, doi:10.1007/s00382-009-0653-1.

Charney, J. G., 1975: Dynamics of deserts and drought in the Sahel. Quart. J. Roy. Meteor. Soc., 101, 193-202.

Chopin, F., J. Berges, M. Desbois, I. Jobard, and T. Lebel, 2005: Satellite rainfall probability and estimation: Application to the West Africa during the 2004 rainy season. Eos, Trans. Amer. Geophys. Union, 88 (Joint Assembly Suppl.), Abstract H23A-12.

Clark, D., and Coauthors, 2011: The Joint UK Land Environment Simulator (JULES), model description-Part 2: Carbon fluxes and vegetation dynamics. Geosci. Model Dev., 4, 701-722.

Cohen, J., 1988: Statistical Power Analysis for the Behavioral Sciences. L. Erlbaum Associates, $567 \mathrm{pp}$.

Cosby, B., G. Hornberger, R. Clapp, and T. Ginn, 1984: A statistical exploration of the relationships of soil moisture characteristics to the physical properties of soils. Water Resour. Res., 20, 682-690.

Cox, P., R. Betts, C. Bunton, R. Essery, P. Rowntree, and J. Smith, 1999: The impact of new land surface physics on the GCM simulation of climate and climate sensitivity. Climate Dyn., 15, 183-203.

de Rosnay, P., and Coauthors, 2009: AMMA Land Surface Model Intercomparison Experiment coupled to the Community Microwave Emission Model: ALMIP-MEM. J. Geophys. Res., 114, D05108, doi:10.1029/2008JD010724.

Dickinson, R. E., A. Henderson-Sellers, C. Rosenzweig, and P. J. Sellers, 1991: Evapotranspiration models with canopy resistance for use in climate models, a review. Agric. For. Meteor., 54, 337-388.

Essery, R., M. Best, R. Betts, P. Cox, and C. Taylor, 2003: Explicit representation of subgrid heterogeneity in a GCM land surface scheme. J. Hydrometeor., 4, 530-543.

FAO, cited 2003: State of the world's forests. UN Food and Agriculture Organisation. [Available online at ftp://ftp.fao.org/ docrep/fao/005/y7581e/.]

Garcia-Carreras, L., D. J. Parker, C. M. Taylor, C. E. Reeves, and J. G. Murphy, 2010: Impact of mesoscale vegetation heterogeneities on the dynamical and thermodynamic properties of the planetary boundary layer. J. Geophys. Res., 115, D03102, doi:10.1029/2009JD012811. 
Gash, J. H. C., and Coauthors, 1997: The variability of evaporation during the HAPEX-Sahel intensive observation period. J. Hydrol., 189, 385-399.

Ghent, D., J. Kaduk, J. Remedios, J. Ardö, and H. Balzter, 2010: Assimilation of land surface temperature into the land surface model JULES with an ensemble Kalman filter. J. Geophys. Res., 115, D19112, doi:10.1029/2010JD014392.

Goutorbe, J. P., and Coauthors, 1997: An overview of HAPEX-Sahel: A study in climate and desertification. J. Hydrol., 189, 4-17.

Grippa, M., and Coauthors, 2011: Land water storage variability over West Africa estimated by Gravity Recovery and Climate Experiment (GRACE) and land surface models. Water Resour. Res., 47, W05549, doi:10.1029/2009WR008856.

Guichard, F., and Coauthors, 2010: An intercomparison of simulated rainfall and evapotranspiration associated with a mesoscale convective system over West Africa. Wea. Forecasting, 25, 37-60.

Houldcroft, C., W. Grey, M. Barnsley, C. Taylor, S. Los, and P. North, 2009: New vegetation albedo parameters and global fields of soil background albedo derived from MODIS for use in a climate model. J. Hydrometeor., 10, 183-198.

Kohler, M., N. Kalthoff, and C. Kottmeier, 2010: The impact of soil moisture modifications on CBL characteristics in West Africa: A case-study from the AMMA campaign. Quart. J. Roy. Meteor. Soc., 136, 422-455.

Koster, R., and Coauthors, 2004: Regions of strong coupling between soil moisture and precipitation. Science, 305, 11381140.

Kothavala, Z., M. Arain, T. Black, and D. Verseghy, 2005: The simulation of energy, water vapor and carbon dioxide fluxes over common crops by the Canadian Land Surface Scheme (CLASS). Agric. For. Meteor., 133, 89-108.

Lauwaet, D., K. De Ridder, and N. P. M. van Lipzig, 2008: The influence of soil and vegetation parameters on atmospheric variables relevant for convection in the Sahel. J. Hydrometeor., 9, 461-476.

Le Barbe, L., and T. Lebel, 1997: Rainfall climatology of the HAPEX-Sahel region during. J. Hydrol., 188-189, 43-73.

Lomb, N. R., 1976: Least-squares frequency analysis of unequally spaced data. Astrophys. Space Sci., 39, 447-447.

Masson, V., J. Champeaux, F. Chauvin, C. Meriguet, and R. Lacaze, 2003: A global database of land surface parameters at $1-\mathrm{km}$ resolution in meteorological and climate models. J. Climate, 16, 1261-1282.

Mougin, E., and Coauthors, 2009: The AMMA-CATCH Gourma observatory site in Mali: Relating climatic variations to changes in vegetation, surface hydrology, fluxes and natural resources. J. Hydrol., 375, 14-33.

Press, W. H., S. A. Teukolsky, W. T. Vetterling, and B. P. Flannery, 1992: Numerical Recipes in C: The Art of Scientific Computing. 2nd ed. Cambridge University Press, 994 pp.

Priestley, M. B., 1979: Spectral Analysis and Time Series. Academic, $890 \mathrm{pp}$.

Redelsperger, J. L., C. D. Thorncroft, A. Diedhiou, T. Lebel, D. J. Parker, and J. Polcher, 2006: African Monsoon Multidisciplinary Analysis: An international research project and field campaign. Bull. Amer. Meteor. Soc., 87, 1739-1746.
Rodell, M., P. Houser, A. Berg, and J. Famiglietti, 2005: Evaluation of 10 methods for initializing a land surface model. J. Hydrometeor., 6, 146-155.

Saux-Picart, S., and Coauthors, 2009: SEtHyS Savannah: A multiple source land surface model applied to Sahelian landscapes. Agric. For. Meteor., 149, 1421-1432, doi:10.1016/ j.agrformet.2009.03.013.

Scargle, J. D., 1989: Studies in astronomical time-series analysis. III. Fourier transforms, autocorrelation functions, and crosscorrelation functions of unevenly spaced data. Astrophys. J., 343, 874-887.

Schulz, M., and M. Mudelsee, 2002: REDFIT: Estimating red-noise spectra directly from unevenly spaced paleoclimatic time series. Comput. Geosci., 28, 2421-2426.

Schüttemeyer, D., A. F. Moene, A. A. M. Holtslag, and H. A. R. de Bruin, 2008: Evaluation of two land surface schemes used in terrains of increasing aridity in West Africa. J. Hydrometeor., 9, 173-193, doi:10.1175/2007JHM797.1.

Sheng, J., and F. Zwiers, 1998: An improved scheme for timedependent boundary conditions in atmospheric general circulation models. Climate Dyn., 14, 609-613.

Sobrino, J. A., and M. Romaguera, 2004: Land surface temperature retrieval from MSG1-SEVIRI data. Remote Sens. Environ., 92, 247-254.

Spracklen, D. V., S. R. Arnold, and C. M. Taylor, 2012: Observations of increased tropical rainfall preceded by air passage over forests. Nature, 489, 282-285.

Taylor, C. M., D. J. Parker, and P. P. Harris, 1997: An observational case study of mesoscale atmospheric circulations induced by soil moisture. Geophys. Res. Lett., 34, L15801, doi:10.1029/ 2007GL030572.

,-- , and -2007 : An observational case study of mesoscale atmospheric circulations induced by soil moisture. Geophys. Res. Lett., 34, L15801, doi:10.1029/2007GL030572.

- A. Gounou, F. Guichard, P. P. Harris, J. Eliis, Richard, F. Couvreux, and M. De Kauwe, 2011: Frequency of Sahelian storm initiation enhanced over mesoscale soil-moisture patterns. Nat. Geosci., 4, 430-433.

— R. A. M. de Jeu, F. Guichard, P. P. Harris, and W. A. Dorigo, 2012: Afternoon rain more likely over drier soils. Nature, 489, 423-426.

Teuling, A. J., S. I. Seneviratne, C. Williams, and P. A. Troch, 2006: Observed timescales of evapotranspiration response to soil moisture. Geophys. Res. Lett., 33, L23403, doi:10.1029/ 2006GL028178.

Timouk, F., and Coauthors, 2009: Response of surface energy balance to water regime and vegetation development in a Sahelian landscape. J. Hydrol., 375, 178-189.

Wallace, J. S., and C. J. Holwill, 1997: Soil evaporation from tiger bush in south west Niger. J. Hydrol., 189, 426-442.

Wan, Z., and J. Dozier, 1996: A generalised split-window algorithm for retrieving land-surface temperature from space. IEEE Trans. Geosci. Remote Sens., 34, 892-905.

Xue, Y., and Coauthors, 2010: Intercomparison and analyses of the climatology of the West African Monsoon in the West African Monsoon Modeling and Evaluation project (WAMME) first model intercomparison experiment. Climate Dyn., 35, 3-27, doi:10.1007/s00382-010-0778-2. 